\title{
Communication and Media
}

\section{Software-Sorted Exclusion of Asylum Seekers in Norway and Finland}

\author{
Funda Ustek-Spilda ${ }^{1}$ (D) ${ }^{a}$, Marja Alastalo ${ }^{2}$ b \\ 1 Oxford Internet Institute, University of Oxford, United Kingdom , 2 University of Eastern Finland, Finland \\ Keywords: double social life of methods, population statistics, norway, finland, refugees, asylum, personal identification number \\ https://doi.org/10.1525/gp.2020.12978
}

\section{Global Perspectives}

Vol. 1, Issue 1, 2020

\begin{abstract}
As James Scott writes, to be able to govern, administrative bodies need to make objects of government legible. Yet migrant persons do not fall neatly into the categories of administrative agencies. This categorical ambiguity is illustrated in the tendency to exclude asylum seekers from various population registers and to not provide them with ID numbers, which constitute the backbone of many welfare states in Europe. Based on ethnographic fieldwork in Norway and Finland, and in Eurostat and UNECE, we study how practices of population registration and statistics compilation on foreign-born persons can be beset by differential and at times contradictory outlooks. We show that these outlooks are often presented in the form of seemingly apolitical software infrastructures or decisions made in response to software with limited, if any, discretion available to bureaucrats, statisticians, and policymakers. Our two cases, Norway and Finland, are considered social-democratic regimes within Esping-Andersen's famous global social policy typology. Using science and technology studies and specifically "double social life of methods," we seek to trace how software emerges as both a device for administrative bookkeeping and also for enacting the "migrant" categories with particular implications for how the welfare state comes to be established and how welfare policies come to be implemented. We note that even if all statistical production necessarily involves inclusions and exclusions, how the "boundaries" are set for whom to include and exclude directly affects the lives of those implicated by these decisions, and as such, they are onto-political. This means that welfare policies get made at the point of sorting, categorizing, and ordering of data, even before it is fed into software and other administrative devices of government. In view of this, we show that methods enact their subjects-we detail how the methods set to identify and measure refugee statistics in Europe end up enacting the welfare services they have access to. We argue that with increasing automation and datafication, the scope of welfare systems is being curtailed under the label of efficiency, and individual contexts are ignored.
\end{abstract}

\section{INTRODUCTION}

In her book Automating Inequality: How High-Tech Tools Profile, Police, and Punish the Poor (2018), Virginia Eubanks sheds light on the increasing automation of public welfare enrollment in the United States. She describes how the welfare enrollment system, which used to be entirely managed by case workers making decisions on an individual basis, is now replaced by algorithmic decision-making systems that prioritize efficiency, management, and quick fixes rather than assessing individual conditions and proposing long-term solutions to systemic problems. Eubanks's book reflects the rising concern about automating what was once referred to as the "decision-making face of the state" (Kangas and Onsér - Franzén 1996). In a recent article series on "automating poverty," the Guardian (2019) also reflected on how automated decision-making systems are changing the focus of welfare from social and economic risk alleviation to surveillance, control, and sanctions and how there is a growing need for human oversight in rolling out and administering these technologies. It is perhaps, then, no surprise that on Thesaurus.com, the antonym of the word "automatize" is listed as "humanize" and "dehumanize." This presumed antagonistic relationship between humans and computers, case workers and software systems, however, requires further elaboration. Studies on algorithmic bias (Bozdag 2013; Mittelstadt et al. 2016; Silva and Kenney 2018) often point out that the data automated decisionmaking systems are trained on does not appear out of nowhere, and that they reflect the attitudes, biases, and approaches of those who design them (Whittaker et al. 2018; Ustek-Spilda, Powell, and Nemorin 2019). But, as CheneyLippold (2017) puts it, in the present day governed by ubiquitous surveillance of algorithms, what data says about us has come to replace who we are (4), and once algorithmic categorization, sorting, and decision-making takes place, it is difficult to shake off, object to, or alter those decisions. As such, algorithms are increasingly enacting a "black box society" whereby neither the data nor the algorithms that make decisions about us are transparent, decipherable, or knowable (Pasquale 2015). Yet autonomous decision-making systems are increasingly celebrated in public gover- 
nance and humanitarian initiatives for being efficient, reliable, and objective as they eliminate human bias, discretion, and clientelism.

In this article, we turn our attention to the production of data on asylum seekers and refugees that is fed into welfare decisions that are made about them, when existing governance structures are moving toward algorithms and autonomous decision-making systems. Our scholarly interest in the field comes amid heightened interest in the counting of asylum seekers and refugees in Europe in the aftermath of the so-called refugee crisis of 2015 (Vis and Goriunova 2015). We contend that, even if all data production necessarily involves inclusions and exclusions, how the "boundaries" are set for whom to include and whom to exclude have immediate effects on the lives of those implicated by these decisions (Bowker and Star 2000).

We propose that with autonomous decision-making systems, inclusion and exclusion decisions predate the analysis; decisions are being made at the moment of data entry rather than once the data is analyzed. This entails that there is little room, if any, to take into account individual circumstances in the decision-making process, when the stress is placed on the averages, expected outcomes, and standard procedures or the contexts in which these data systems are developed. We argue that this logic of datafication and automatization leads to further dismantling of the welfare state as decisions for welfare provisions are made based on meeting data requirements, rather than on individual needs or circumstances, or universal access as a right. In other words, data-based systems are not expanding the scope of welfare systems thanks to more efficiency in the use of resource allocation, but instead help curtail them further by reducing (or eliminating) the possibility of taking individual circumstances into account.

\section{DIFFERENTIAL ACCESS TO WELFARE AS A FORM OF INJUSTICE AND INEQUALITY}

Social policy theory problematizes the "equal worth of every citizen" (see Pierson and Castles 2009, 53). For instance, Pierson and Castles $(2009,53)$ argued that social justice is generally "thought to have something to do with equality," but it is more about "equality of opportunity" given the increasingly limited resources available to welfare states. The authors stressed that not all inequalities are unjust and that the provision of welfare states should not be to erase all inequalities, but to erase only those that are unjust and as such prevent equality of opportunity (60-61).

In drawing the attention to citizens' ability and drive to make the most of the opportunities granted to them, we think that the authors overlook a central issue. For those who do not enjoy the rights of citizenship in a country as full citizens, it is rather difficult to differentiate equality from equality of opportunity, inequality from injustice.

Earlier, Bloch and Shuster (2002) had argued that differential treatment of varying citizenship statuses entailed the increasing exclusion and marginalization of asylum seekers in Europe, and that curtailment of welfare services was jus- tified through disincentivizing asylum applications in European member states (also see Thränhardt 1999). The authors drew attention to the contradictions that underpin welfare state regimes: on the one hand, they serve to protect the citizens against social and economic risks (e.g., the poor, women, migrants, etc.); on the other hand, they maintain the exclusion of the same groups through defining who is part of the nation-state (and hence eligible for welfare state provisions) and who is not (Thränhardt 1999). More recently, Mayblin (2016) drew attention to the differential access of asylum seekers to the labor market in the United Kingdom as a way of maintaining a distinction between citizens who "belong" and noncitizens who do not (stress original).

\section{METHODS}

We bring together data from two ethnographic research projects that are concerned with how populations are enacted through the practices of registration and statistical data production. One of the studies, ARITHMUS: How data make a people (ERC 2014-19), ${ }^{1}$ explored the work of five national statistical institutes (in the United Kingdom, Netherlands, Estonia, Turkey, and Finland) and two international statistical organizations (UNECE and Eurostat) through a collaborative ethnography in their efforts to define, categorize, identify, and harmonize population statistics, and paid close attention to the production of migration and refugee statistics. The data presented in this article for the Norwegian case study draws on a corpus of fieldwork notes, interview transcripts, and participant observations in national and international meetings on migration and refugee statistics, as well as secondary data analysis of reports, legislations, and guidelines developed and recommended by statisticians in the field between 2014 and 2017. Here, Norway was not initially one of the countries of study for the project, but it became a central country of analysis as Norway led the organization of the Expert Group on Refugee and IDP (Internally Displaced Persons) Statistics (EGRIS) in Europe because of their highly developed systems for refugee registration and statistics. We have conducted interviews at Statistics Norway and UDI: The Norwegian Directorate of Immigration, and also observed other experts working for humanitarian agencies and international organizations as part of the EGRIS meetings.

The second study, "Mobile People-Challenging the population statistics and projections," 2 was concerned with the state registration and knowledge production practices in Finland, with particular attention paid to the practices involved in registration of migrants, population registerkeeping, and statistics compilation at the national level. The analysis in this article for the Finnish case study draws on audio-recorded and transcribed interview data (sixteen officers at the Local Register Offices, five officers at the Population Register Centre, ${ }^{3}$ five officers at Statistics Finland, and sixteen foreign-born persons residing in Finland) and 104 audio recordings and observations of registration en-

1 The ARITHMUS project studied how methodological changes in the production of population statistics within the European Union have consequences for the enactment of populations as objects of government. The project principal investigator was Professor Evelyn Ruppert (Goldsmiths, University of London).

2 The project principal investigator for “Mobile People-Challenging the Population Statistics and Projections” was Dr. Marja Alastalo.

3 The Population Register Centre and the Local Register Offices were merged in the beginning of 2020 to form a new institution called the Digital and Population Data Services Agency. Despite this merger, the organization and tasks regarding the migrant registration and register keeping have remained the same. We use the former names only in this description of the fieldwork. 
counters between officers and migrants at the Local Register Offices, as well as observations both at the Population Register Centre and at Statistics Finland. Furthermore, it was informed by secondary analysis of extensive documentary data involving national and EU legislation on the registration of asylum seekers and refugees; guidelines and instructions given to local register offices by the Population Register Centre as well as the metadata of the registration process; and finally by follow-up email conversations with four officers from the Population Register Centre, Statistics Finland, Finnish Migration Service, and the Social Insurance Institution of Finland during fall 2019.

In what follows, we first present our theoretical approach that draws from STS (science and technology studies) to the differential inclusion and exclusion of asylum seekers in the context of welfare states in Europe with a focus on Nordic welfare states. Second, we look at "usual residence" as a statistical concept that shapes current inclusion and exclusion decisions in population statistics in Europe. Third, we present two particular cases of exclusion of asylum seekers from welfare state services and statistical populations in two Nordic countries in Europe: Finland and Norway. We then conclude with a discussion on the implications of our findings for rethinking social justice in the context of contemporary welfare states today.

\section{THE ONTO-POLITICS OF INCLUSION AND EXCLUSION IN POPULATION STATISTICS}

In his famous book The Three Worlds of Welfare Capitalism (1990), Esping-Andersen builds a typology of welfare states in the world based on the concept of "decommodification," which he defines as occurring "when a service is rendered as a matter of right, and when a person can maintain a livelihood without reliance on the market" (22). He adds that the mere presence of social assistance (or insurance) in itself does not guarantee decommodification if they do not emancipate individuals from their dependence on the market (22), and the kind of social stratification and social solidarities that exist in the country should also be taken into consideration. The differences between contemporary welfare states, he argues, can be analyzed through how much decommodification they provide to their citizens (as well as their commitment to full employment [132]) and how they do (or do not) support the emergence and existence of social solidarities. His analysis reveals three types of welfare states: (1) liberal, (2) conservative/corporatist, and (3) social democratic, where liberal welfare states ensure the least amount of decommodification and mostly rely on means-testing for the provision of welfare services; and social democratic welfare states provide the highest amount of decommodification based on citizenship rights. The case studies we analyze in this article, Finland and Norway, have both been categorized as social democratic welfare states, as there is a wide range of welfare state services available to citizens that are not based on means-testing or aid-based assistance. More recently, however, due to ongoing welfare retrenchment in these countries, researchers have started to ponder if they align more with (neo)liberal or conservative welfare models (see Kvist and Greve 2011; Baeten, Berg, and Lund Hansen 2015) and to what extent a gradual restructuring of the welfare state took place in these countries (Tervonen, Pellander, and Yuval-Davis 2018).

The ongoing retrenchment in European welfare states aside, Esping-Andersen's typology has been criticized for a variety of reasons: for overlooking women's unpaid labor (Crompton 1998; Lewis 2006; Orloff 2009); for ignoring welfare state systems in the developing world (Midgley 1997; Gough 2013), Mediterranean countries (Gal 2010), post-socialist countries (Fenger 2007), or Asian countries (Goodman, White, and Kwon 1998). ${ }^{5}$ But even these criticisms and critiques continued to approach the issue through the lens of those who have the right to remain in the countries in question, and overlooked the cases of those with limited (or no) access to the labor market or social assistance services due to their residency status. This has actually reflected in the migration regime types that were developed from Esping-Andersen's welfare state typology (see Boucher and Gest 2014 for a discussion; see also Horvath, Amelina, and Peters 2017), even though reassessments of the welfare state regimes based on their inclusion and exclusion of different migrant groups remains a gap in the literature.

One of the main challenges for developing such a typology lies in the plethora of categories and classifications in place for referring to different types of migration. For instance, while "asylum seeker" and "refugee" status exist as categories with legal connotations, an asylum application can result in a variety of outcomes. ${ }^{6}$ It might result in refugee status, humanitarian assistance, or temporary humanitarian assistance, or it might be rejected. If rejected, an individual can decide to appeal, and when appeal routes are exhausted, an individual might be returned or allowed to remain, if their return would be considered a life-threatening risk (Ustek-Spilda 2019). This is also where the power of administrative (and also legal) categories lie, as they shape the perception of what it means to belong to a certain group and instill incentives for becoming part of a collective community but also fuel divisions among the people (Vetters 2007).

The "boundary-making" in categories becomes thorny both when governments decide who gets to be included in/excluded from a category-and with what effects (e.g., refugee or asylum seeker)-and how these inclusions and exclusions impact policy-making in general. Leibler and Breslau (2005, 880-81), for instance, document how those absent during the 1948 census (and hence not counted as part of the "resident" category) in Israel were excluded from the target population, their rights to citizenship forfeited and their ownership of goods, property, and land no longer recognized. Similarly, Christopher (2009) shows how in the course of the last 140 years, census boundaries have exclud-

\footnotetext{
4 Riikka Homanen conducted fieldwork at the Local Register Offices and foreign-born persons were interviewed by Anitta Kynsilehto and Pekka Rantanen.

5 See Arts and Gelissen (2002) for an extensive overview of Esping-Andersen's welfare state regimes and its critiques.

6 In this article, we follow EGRIS (2018) definitions for refugee and asylum seeker. A refugee is someone "who, owing to a well-founded fear of being persecuted for reasons of race, religion, nationality, membership of a particular social group, or political opinion, is outside the country of his nationality, and is unable, or owing to such fear, is unable to avail himself of the protection of that country" (20), and an asylum seeker is someone who is "claiming or applying for protection as a refugee and who has not yet received a final decision on his or her claim. It can also refer to someone who has not yet submitted an application for refugee status recognition (has not yet formalised the administrative requirements in national law) but nevertheless be in need of international protection" (22).
} 
ed and included different groups based on the definitions used for "the nation" and its territorial boundaries-ranging from counting only the white population to more inclusive enumerations in South Africa.

Categories and classifications, however, are but one of the many devices that have been utilized in the operations of the state (Caplan and Torpey 2001). Personal identification numbers, birth certificates, ID cards, passports, visas, social insurance numbers, and even the concept of a permanent surname have all been part and parcel of the state infrastructure in the ways in which states have attempted to make populations "legible," thus "governable" (Scott 1998). Those that do not "fit" end up getting excluded, not only from the measurement but also from services, benefits, and rights that are tied to that measurement. As such, population measurement methods are performative: they enact the realities they are set to measure, count, and represent (Law 2004). This understanding of performativity of methods makes up what Law, Ruppert, and Savage (2011) name as "double social life of methods." Challenging the binary divide between reality and its representations, the authors take issue with social research that oscillates between objectivity and constructivism, and instead argue that methods are social because, first, "they are constituted by the social world they are a part," and second, "they help constitute that world" (4). This is not a simple constructionism, however, nor does it entail a variety of relativism. Because each method comes with its own "hinterland" and "assemblages," knowing differently would entail uprooting all the hinterland of a method, including its experts, advocates, standards and practices, and established practices (Law 2004).

Categories and classification systems of government are not simply top-down systems of ordering. Even when people take classifications to be simply formal or bureaucratic, they also mold their behavior to fit those conceptions (Bowker and Star 2000, 54) or reject them (Cakici and Ruppert 2020). In other cases, categories can also trigger new categories to being. For instance, Ruppert (2008) shows how the category "Canadian" became the fastest growing "ethnic" category in Canada by the end of the twentieth century, even though the census actually discouraged and advised against using the category in the official classification of racial and ethnic origins. Ruppert argues that the category part enacted the Canadian as a group, who before the category might not consciously associate with it.

With the move toward automated decision-making systems, these performativity effects of categories and the technologies used to sort, categorize, and filter data have been exacerbated, whereas the space for individuals to challenge, alter, and reject them has diminished. As CheneyLippold (2017, 15-16) explains, data has come to be associated with truth, as scientific positivism demands that we let data speak for itself. But as he rightly states, the categories people are assigned in data do not actually speak for themselves; they are "collected by humans, manipulated by researchers and ultimately massaged by theoreticians to explain a phenomenon" (Cheney-Lippold 2017, 15-16). In the context of refugees and asylum seekers, Madianou (2019) argues that the "biometric assemblage" of new technologies that includes blockchain, biometrics, and artificial intelligence amplifies the risks associated with each constituent technology, with direct implications for the security, pri- vacy, and dignity of refugees-as they reproduce the existing power asymmetries between refugees and humanitarian agencies. Against this background, we aim to expose the workings of categorization of asylum seekers in the context of Nordic welfare states by tracing both the statistical and administrative practices that together enact-especially in the register-based statistical systems-objects that are simultaneously real and constructed. In the Nordic registerbased statistical system where the register data is produced by and for the immigration management authorities, the categories created in and for the (juridico-) administrative practices travel easily to population statistics and continue to influence the welfare policies at the population level. Moreover, Nordic countries are leading the way for registerbased systems to be adopted in other countries in Europe (but also outside Europe)-as registers are being celebrated for their efficient production of statistics at a low cost and ability to produce "a complete picture" of individuals throughout their life span in a country.

\section{ASYLUM SEEKERS AS UN-USUAL RESIDENTS}

States have been nothing but the enemy of "people who move around," Scott $(1998,1)$ writes. Indeed, the plethora of categories and definitions used in a population to identify, sort, and categorize mobile individuals reveals how one of the main assumptions of population statistics is that individuals can be pinned to one location (country) of birth with one stable home address.

The measurement of a population in a country takes the form of various categorizations, and depending on the population of interest, different characteristics and values are prioritized. One important source of sorting in population statistics happens when establishing the "population base." Broadly, the population base refers to the "population to be enumerated" in a country (UNECE 2015, 76). Although countries may adopt more than one population base, "usually resident population" (URP) is recommended for international comparison (UNECE 2015, 78). ${ }^{7}$ There are two important definitions for measuring URP. The "place of usual residence" means "the geographic place where the enumerated person usually spends their daily rest, assessed over a defined period of time, including the census reference time" (UNECE 2015, 78, para. 392), and "the usually resident population" is composed of those "who have lived, or intend to live there [in their place of usual residence] for a continuous period of at least 12 months" (UNECE 2015, 78, para. 393).

The guideline for establishing URP recommends that "persons who may be illegal, irregular or undocumented migrants, as well as asylum seekers and persons who have applied for, or been granted, refugee status or similar types of international protections, provided that they meet the criteria for the usual residence in the country" should be included in the URP even when they cannot be distinguished separately (UNECE 2015, 80). Previous research shows, however, that asylum seekers are more often excluded from population bases, rather than being included in them (Ustek-Spilda 2019). UNECE acknowledges the difficulties of measuring the stock of refugees (persons whose asylum applications have been accepted under national regulations and/or international conventions) and asylum seekers (persons whose applications have not been determined) because of their mobility and the changes in the formal status 
given to refugees (UNECE 2015, 144). As they explain, this is because countries may use different definitions for establishing the category of refugees to include and exclude in their specific legal and administrative contexts (144). Individuals may also identify themselves differently from their legal status (144). This is why persons with a refugee background-those individuals who have experienced (directly or indirectly) a forced migration-are considered as part of refugee statistics (144), even though their applications for asylum may still be pending or rejected or they might have been given temporary protection status. This is also the reason why the term "refugee and refugee related populations" is used by EGRIS instead of identifying or seeking internationally commensurate equivalents of national legal and/or administrative categories (EGRIS 2018, 27).

Due to space limitations, we are unable to give a full account of the range of population enumeration methods used in Europe and their implications for the counting of asylum seekers and refugees. Nevertheless, it is important to specify that a majority of countries in the world (and in Europe) use one of the following three methods: a traditional census, where the enumeration relies on field enumeration of all residents on the census enumeration day (or period); a register-based census, where population registers (e.g., birth, date, tax, employment, etc.) constitute the backbone of the census; or a combined method, where some of the details required for census are obtained from registers and the others are supplemented by traditional survey and other field enumeration methods.

Increasingly, many countries are moving toward a register-based census due to its high efficiency, timeliness, and low costs; Nordic countries are presented as the example to follow with their established register systems. Each of these methods reveal different inclusions and exclusions of asylum seeker and refugee populations. For instance, in traditional censuses, countries have a choice in either conducting a census based on the URP category and definition (de jure) or based on counting those present at the time of the census (de facto). According to Bruce Curtis (2001, 26), these two types of censuses configure social relations into a population through categorizing individuals based on either where they may reasonably expect to be habitually or where they have a right to be. Given that URP is recommended by UNECE and Eurostat for international comparison, countries increasingly prefer this method as it is also said to offer a better account for planning and policy purposes (EGRIS 2018, 45-46). However, the choice has an immediate effect on refugee statistics. In traditional censuses, issues related to the discrepancies between how individuals identify themselves (e.g., refugee, asylum seeker, and so on) might not always mirror their legal status in the country, which the administrative data is based on (EGRIS 2018, 49). Moreover, issues related to field enumeration, such as language barriers or suspicion toward and avoidance of government questionnaires, may also result in exclusion of asylum seekers and refugees (EGRIS 2018, 49).

Register-based population censuses, too, enact different inclusions and exclusions when enumerating asylum seeker and refugee populations. One of the most important considerations here is that statistics derived from regis- ters-which are usually set up for administrative rather than statistical purposes-reflect procedures rather than people (EGRIS 2018, 63). For instance, they might have records of a family filing an asylum application, but not necessarily individual files for each member of the family (EGRIS 2018, 63). In addition, administrative data often relates to the registration information collected by a specific administration (e.g., border police) in a particular circumstance but does not necessarily include information related to other topics (e.g., granted residency status, educational background, employment history, etc.), which might play an important role for planning and policy-making (EGRIS 2018, 64). Moreover, time lag between data collection and extraction may result in undercounting of populations (64), especially during times of high mobility, or double-counting, if the data are not linked and individuals are counted multiple times by different administrative registers (64).

\section{PERSONAL IDENTIFICATION NUMBER IN THE NORDIC WELFARE STATES}

Population statistics have a direct implication on policymaking, from allocation of resources to planning of services, from access to the labor market to receiving welfare services. In what follows, we will explore how inclusion and exclusion from statistics is tightly connected to inclusion and exclusion from the welfare state for asylum seekers in Finland and Norway. Although we recognize that there are differences between Nordic countries (see Greve 2007), they also share important similarities in terms of the organization of labor markets and residence-based welfare provision (Greve 2007; Kettunen and Petersen 2011) and the methods they use for population enumeration (i.e., register-based). Their approaches to migration are also similar, in that migration is increasingly controlled and access to welfare state services for those with "uncertain" statuses is restricted (Tervonen, Pellander, and Yuval-Davis 2018).

One important system Nordic welfare states have is the established history of personal identification number (PIN) and national population registers dating back to the 1960s. Population statistics in these countries are strongly linked to the population registers, as most population statistics are produced through retrieving data from the registers (except specialized surveys) (UNECE 2007). Civil registration number (Det Centrale Personregister nummer, or CPRnumber) in Denmark; national identity number (Fødselsnummer) in Norway; personal identity number (Personnummer) in Sweden; and personal identity code (Henkilötunnus, abbreviated as HETU) in Finland are personal identifier numbers, usually eleven digits, used to identify and link individuals across various administrative databases. Citizens of these countries (both by birth and by naturalization) are issued with a PIN. Usually the first six digits represent the date of birth (in the order of day, month, year); the next three digits indicate gender (even numbers for women and odd numbers for men); and the last five digits constitute the personal number, with the last two digits being control digits. ${ }^{8}$ For instance, from the number 01129955131, it can be deduced that the person was born on 1 December 1899 and is male. ${ }^{9}$ Although an eleven-digit se-

8 For a detailed explanation of the Finnish PIN, see https://vrk.fi/en/personal-identity-code1, accessed 22 November 2019; for the Danish CPR-number, see https://cpr.dk/media/17535/erstatningspersonnummerets-opbygning.pdf, accessed 21 November 2019.

9 Norwegian Tax Administration, accessed 21 November 2019, https://www.skatteetaten.no/en/person/national-registry/birth-and-nameselection/children-born-in-norway/national-id-number/. 
Table 1: 1 History of Registers and their use in censuses in Nordic Countries (modified from: UNECE 2007, 5).

\begin{tabular}{|c|c|c|c|c|c|c|c|c|}
\hline \multirow[b]{2}{*}{$\begin{array}{l}\text { Type of } \\
\text { register }\end{array}$} & \multicolumn{2}{|c|}{ Denmark } & \multicolumn{2}{|c|}{ Finland } & \multicolumn{2}{|c|}{ Norway } & \multicolumn{2}{|c|}{ Sweden } \\
\hline & $\begin{array}{l}\text { Estab- } \\
\text { lished }\end{array}$ & $\begin{array}{l}\text { First } \\
\text { used in } \\
\text { census }\end{array}$ & $\begin{array}{l}\text { Estab- } \\
\text { lished }\end{array}$ & $\begin{array}{l}\text { First } \\
\text { used in } \\
\text { census }\end{array}$ & $\begin{array}{l}\text { Estab- } \\
\text { lished }\end{array}$ & $\begin{array}{l}\text { First } \\
\text { used in } \\
\text { census }\end{array}$ & $\begin{array}{l}\text { Estab- } \\
\text { lished }\end{array}$ & $\begin{array}{l}\text { First } \\
\text { used in } \\
\text { census }\end{array}$ \\
\hline $\begin{array}{l}\text { Central } \\
\text { Population } \\
\text { Register }\end{array}$ & 1968 & 1981 & 1969 & 1970 & 1964 & 1970 & 1967 & 1975 \\
\hline $\begin{array}{l}\text { Business } \\
\text { Register }\end{array}$ & 1975 & 1981 & 1975 & 1980 & 1965 & 1980 & 1963 & 1975 \\
\hline Education & 1971 & 1981 & 1970 & 1975 & 1970 & 1980 & 1985 & 1990 \\
\hline Employment & 1979 & 1981 & 1987 & 1990 & 1978 & 2001 & 1985 & 1985 \\
\hline Family & 1968 & 1981 & 1978 & 1980 & 1964 & 1980 & 1960 & 1975 \\
\hline Income & 1970 & 1981 & 1969 & 1970 & 1967 & 1980 & 1968 & 1975 \\
\hline $\begin{array}{l}\text { Totally } \\
\text { register-based } \\
\text { census }\end{array}$ & & 1981 & & 1990 & & 2011 & & 2011 \\
\hline
\end{tabular}

quence number has been considered to be sufficient to enumerate the populations, in 2007 Denmark ran out of unique sequence numbers to be allocated to males born on 1 January $1965 .^{10}$ The first of January was the first birth date to run out of sequence numbers because immigrants who do not know their exact date of birth or do not have documents that can prove their date of birth are usually assigned this date during registration. ${ }^{11}$ The Danish case, however, revealed the possibility of running out of numbers and the potential need to alter the system because of immigration.

The PIN and the centralized population registers are integral to life in Nordic countries. At the individual level, it is virtually impossible to access any government or private service without a PIN. From opening a bank account to registering for a school, from taking up employment and paying taxes to accessing the healthcare system, with some variation between the countries, the PIN serves as both a key for identifying residents in the country and an accountability mechanism that ensures that only those whose residences are registered can access the welfare services. At the administrative level, the PIN ensures that all government (and private) databases can speak to one another, as the same individual can be traced and tracked through various databases. These traces are sometimes referred to as "signs of life"; ${ }^{12}$ it is expected that if an individual is alive and a resident, she will leave traces in at least one (or more) administrative databases by going to a school, seeing a doctor, paying taxes, voting, or paying a utility bill. As such, the PIN also helps government departments to keep an up-todate record of residents. The ubiquity of the PIN, however, also entails that those without it get barred from accessing welfare services, regardless of their needs or their specific conditions. It also entails that the PIN is often seen as a merely technical inscription device (Law 2004), and the ex- tent to which it affects everyday life becomes invisible. Indeed, for those who have the PIN, life as usual works seamlessly and effortlessly. It is for those who do not have a PIN that life becomes difficult and wreathed with suspicion, distrust, and uncertainty.

While register-based systems are considered to be the future of statistical systems in Europe (and the world), there is an increasing discussion about supplementing them with Big Data, as it provides timely analysis of population trends. Hence, there are currently various ongoing projects for predicting migratory movements through mobile phone data or understanding the composition of mobile populations through migrants' Facebook posts and online searches (see also Madianou 2019). International organizations that are part of the EGRIS group are working on projects that integrate blockchain, machine learning, and algorithms into their data storage and analysis. ${ }^{13}$ In Nordic countries where there is existing traceability of individuals via the PIN, those without a PIN are emerging as "anomalies." Aradau and Blanke (2018) explain that rather than the enemy or the risky abnormal, the "other" is algorithmically produced as "irregular existence." As such, they become particularly desirable to track by security professionals (Aradau and Blanke 2018) and to tame by policymakers.

\section{FINLAND: KEEPING POPULATIONS APART}

In 1990 Finland became the second country in the world after Denmark to move to a fully register-based population census. Since then, population statistics have been compiled on the data drawn from the population information system (hereafter, population register). The national centralized population register-which works as a state identity management system-has been characterized as a basic in-

10 Det Centrale Personregister, “Første personnummer uden modulus 11 kontrol er nu tildelt,” 1 October 2007, accessed 21 November 2019, https://web.archive.org/web/20110719122205/http://www.cpr.dk/cpr/site.aspx?p=174\&t=visartikel\&Articleid=4347

11 In Finland, 31 December is assigned as the birth date of asylum seekers who do not have ID cards to prove their date of birth. During our fieldwork, this was mentioned to us as a way of identifying someone's asylum background. Fieldwork notes, Statistics Finland, 2015.

12 Fieldwork notes, Statistics Norway, April 2017, and Statistics Finland, 2015.

13 Participant observation, EGRIS Meeting, Oslo, Norway, April 2017. 
frastructure of the state. The population register is claimed to contain "basic information about Finnish citizens and foreign citizens residing in Finland on a permanent or temporary basis."14 In legal terms, the register data is considered "publicly reliable," which means that public authorities can make decisions about individuals on grounds of the data entered into the register. From the outset the population register has been widely used throughout public administration, but the development and implementation of IT and software applications (for instance, the VTJ query interface $)^{15}$ during the 2000 s has made it even more pervasive as users have fast real-time access to register information. What is characteristic to Finland is that the PIN is also widely used by private businesses: mobile phone operators, insurance companies, and numerous other institutions use it in their customer registers. Thanks to the integrated systems, they can update their customers' name and address from the population register via the service provided by the Digital and Population Data Services Agency.

Even though the Digital and Population Data Services Agency explicitly purports that the population register also contains basic information on foreign nationals, the story is different for refugees and asylum seekers. For a small number of so-called quota refugees (or government-assisted refugees, as they are sometimes referred to (e.g., Mountz $2011 b)$, the procedure is rather simple as their need for international protection is already verified by the UNHCR before their arrival in Finland. Because they have been granted asylum, they can request to have their personal information entered into the population register at a local register office (now at a local office of the Digital and Population Data Services Agency) and get permanent residency status and the KELA card, ${ }^{16}$ which together guarantee full access to health and social welfare services and mean that they are also counted in the population statistics and included in the sampling frames.

In comparison, asylum seekers are in a more precarious situation even though, as mentioned above, they have a legal right to stay in the country during the application process. Despite the government's post-2015 eagerness to speed up the process to reduce costs, asylum applications can take several years. During asylum seekers' lengthy waiting period (e.g., Mountz 2011a), a lot of information on them is entered into the Finnish Immigration Service's registers to process their applications on an individual level but also to steer, plan, and monitor "the reception and assistance of international protection applicants, recipients of temporary protection and victims of human trafficking" as well as to ensure "the security of the state." The Finnish Migration Service intends to implement automated decision-making in residence permit processing in 2020, but it would require new legislation.

In relation to the population register, the basic principle is that an asylum seeker is registered after she is granted asylum - that is, when given refugee status. However, during the asylum process, an asylum seeker can be registered as a temporary resident and get a PIN if she has a legitimate reason to request it (for instance, a job offer) and a valid travel document (which four out of five asylum seekers do not have). As a result, different authorities (e.g., tax administration, health care) can assign temporary ID numbers to asylum seekers without valid travel documents. Since temporary IDs are sector specific, one person can have several temporary IDs. ${ }^{17}$ Considering that the databases are otherwise centralized and connected, the fact that asylum seekers can be issued several temporary IDs causes ambiguities.

Asylum seekers face further ambiguities as they navigate the social security systems. Because the PIN emerged along with the institutionalization of social security provisions in the 1960s, it was called the social security number for years. Still, although the PIN has lost the direct connection to welfare entitlement, laypersons and even civil servants sometimes erroneously use the old term "social security number." According to our interviews and field observations, this creates confusion and false expectations among asylum seekers. ${ }^{18}$ With respect to welfare provision, asylum seekers (except for minors) are only entitled to urgent healthcare services. Unlike the permanently residing population whose welfare provisions are covered by the Ministry of Social Affairs and Health, the Ministry of Interior is responsible for the health and social service expenses for persons seeking international protection.

Nevertheless, according to Finnish legislation, asylum seekers cannot be registered in the population register as permanent residents (and can only on certain conditions get a PIN as temporary residents). This means that they are also excluded from the statistical population. Consequently, they are pushed into a state of exception where they are not counted in the statistical population even though their stay might exceed the twelve-month limit of usual residence specified in the EU statistical legislation described earlier.

The exclusion from the statistical population does not mean total absence of statistics, however: The Finnish Immigration Service releases the statistics on "international protection" based on the alien register data. The figures released count not the number of persons but the administrative measures they are subjected to-that is, the number of asylum applications and positive/negative decisions made per month/year. Consequently, the annual and monthly figures are difficult to interpret and easy to misinterpret as one person can lodge more than one application per year and as a result receive several decisions. Thus, the invisibility in the population statistics does not imply that asylum seekers are fully invisible in the statistical knowledge, but they are kept apart from the URP population both in the registers and the statistics and seen through the administrative measures they are subjected to. In short, the in-

14 A description of Population Information System on the Digital and Population Data Services Agency's webpage, accessed 13 February 2020, https://dvv.fi/en/population-information-system /.

15 Search services of the Population Information System, accessed 14 February 2020, https://dvv.fi/en/search-services-of-the-population-information-system/.

16 A refugee has to apply for the Kela card, which is granted by the Social Insurance Institution of Finland. It is not given automatically.

17 A lawyer informant mentioned that in principle, the temporary IDs should not be given to customers themselves (email conversation, November 2019).

18 But as often happens, the attempts to govern and control meet resistance: the wide use of the PIN has also generated creative responses such as PIN generators (see, e.g., http://id-check.artega.biz/). At the time of writing, we do not have information about how these generators have been used and who has used them. 
creasing datafication of the information collected on asylum seekers does not necessarily lead to their increasing access to welfare services, or streamlining the process to understand their needs and circumstances. Rather, what we observe is that their individual needs or circumstances are treated as mere "data points" and not necessarily evidence for evaluating their needs. In this regard, collecting all these different data appears more like a means for heightened control, surveillance, and bordering than a means to establish asylum as a human right (Madianou 2019).

\section{NORWAY: THE PIN AND THE POLITICS OF SMALL NUMBERS}

The PIN is also central to the production of statistics and access to welfare in Norway. And, similarly to Finland, asylum seekers are not issued with a PIN. A statistician at Statistics Norway clarified that this is because "asylum seekers do not have legal residency. When they become refugees, they get their registration and then they are included [in population statistics]." ${ }^{\prime 19}$ He added that URP does not have a direct translation and correspondence in the Norwegian context, and he thought that including asylum seekers in population statistics generated "a lot of extra work with very few benefits." When asked why it was so, he explained: "the number of asylum seekers at any given time who have waited at least one year in Norway is a very small number. Currently [in 2017] it is around a thousand or more, but that is because they [UDI] got a huge flow recently. But very soon, they will get on with these numbers too. It is not difficult to find the figure, but to find individual data is a lot of work." ${ }^{20}$ The uncertainty of the residence of asylum seekers in Norway was often put forth as a reason for not issuing them with a PIN: "most will get rejected anyway," and "generally the numbers are small." ${ }^{21}$ But not having access to a PIN, as in the case of Finland, means that access to welfare services is severely limited. In this section, rather than repeating the same processes of exclusion through a PIN, we will look into how software-sorted exclusion takes place in practice.

In a group meeting on population statistics in 2016, a statistician commented that "IT [information technology] is a priority now (for statistics) and not the other way around." 22 Though the statistician's comment included a touch of sarcasm, discussions about "modernizing" existing statistical systems and methods often go hand in hand with a strong emphasis on "statistical business process models" ${ }^{23}$ or "business intelligent software" 24 that speeds up the operation of data management and cuts down costs. So whether it is discussing how to utilize off-the-shelf business solution packages or transitioning from commercial software to open software ${ }^{25}$ discussions about the future of statistics and data production for government institutions are reminiscent of those happening in the industry, with words such as "disruption," "agile," and "efficient" being central to discussions.

In an interview with a statistician at UDI, he described the "business intelligent software" they recently acquired. He walked us through how the software organizes their workflow between different departments within UDI and between government departments. He noted that he could see and track who is who-including the asylum seekers registered with the police, the detailed reports the police write about individuals, where the asylum seekers are staying at any moment, and how long they have been there, as well as if they have family in Norway. He added that, thanks to the software package, now they were on top of their schedules and everyone's work was transparent as the software was updated every night. This entailed that they received data about asylum applications each night. ${ }^{26} \mathrm{He}$ carefully explained to us how this kind of speed in data exchange was extraordinary and how it significantly improved the possibilities of checking and correcting any data that was wrongly entered into the system or teasing out false applications. Put simply, the software enabled him "to see the problem even before it is a problem." In order to illustrate how the software works, he pointed us to his screen. He clicked on the name of a person, and then a personal page appeared. On the top right, there was a photo; details about the person appeared below. As he was scrolling through the page, he pointed out that this was one of the "flagged" cases because although the person asked to apply for asylum, once his details were entered into the system, it appeared he was Australian. The statistician then explained that he found it confusing that someone from Australia might apply for asylum and asked himself: "Is this a normal occurrence? Are there developments in Australia that might warrant this application?" He then answered that his judgment was "no," and the decision on this application would be "Expulsion. He is not the guy he claims." That there are attempts to make false claims of asylum in itself is not new. Statisticians and bureaucrats working in the field often mention the difficulties of separating "deserving refugees" from those who are not (Griffiths 2012). But software sorting introduces a new capability, where the sociotechnical infrastructures that make up the software systems prescreen, identify, and sort "deservingness" before case workers make their decisions. As Aradau and Blanke (2018) explain, this judgment on deservingness or undeservingness is part of the logic of security where the "undesirables" and risky selves need to be monitored, corrected, or excluded based on the anticipation of their future behavior.

Software, however, does not magically decrease the workloads of case workers. In fact, it adds new tasks. While before the introduction of the business package, the border police were not responsible for entering each interview detail into the categories required by the software, and it was sufficient for them to share the initial interviews with UDI, now they have to do this work. As a result, "when they [the police] cannot be bothered to enter details, they tend to hit 'other."' ${ }^{27}$ This does not constitute a problem when cases are in the "obviously reject" category-but not all cases are. As a result, individual details and contexts that

\footnotetext{
19 Interview, Statistics Norway, March 2017.

20 Interview, Statistics Norway, March 2017.

21 Interview, UDI: Norway, March 2017.

22 Fieldwork notes, February 2016.

23 UNECE “Generic Statistical Business Model” Report, 2013. Obtained via fieldwork in 2017.

24 Fieldwork notes, June 2016.

25 Interview, UDI: Norway, April 2017.

26 Interview, UDI: Norway, April 2017.
} 
strongly shape the outcome of any asylum application get lost. Roberts and Elbe (2017), following Antoinette Rouvroy (2013), refer to this as "proxy data," or "knowledge without truth," noting that knowledge produced by algorithmic processes increasingly escapes the previous systems of verification. In this case, it also entails that individuals' possibilities of challenging the way they are categorized, sorted, or filtered in data become increasingly difficult or, in fact, impossible. "Safe country" lists are produced at the international level, but they do not always coincide with the personal experiences of individuals in those countries. When software sorts individuals a priori without hearing the reasons for their asylum applications, the decisions made based on the data generated by this software get "blackboxed" (Pasquale 2015) and become opaque, illegible, and more importantly, unobjectionable.

Moreover, these systems are increasingly shared across institutions within national jurisdictions but also across international organizations. The statistician we interviewed at UDI, for instance, also described to us that through the shared EASO (European Asylum Support Office) database within Europe, they could see that one person who applied for asylum in Norway had already applied in Germany. Once this was found out, they could immediately refuse the application and return the person to Germany. In his words, the shared software infrastructure within Europe and the Dublin Agreement ${ }^{28}$ were helping prevent "asylum shopping" between countries, which used to be common; previously "One could live his whole life hopping from country to country in the EU; submitting an application, then appeal, then another appeal; then hop to another country and do the same-until it worked out. Did it not work again? One could hop on to another country," but this was no longer the case.

There is increasing awareness that the Dublin system puts the burden on border countries such as Italy and Greece. But according to statisticians, this is all the more reason to improve the "quota system" in Europe-where each country gets allocated a set number of asylum seekers, regardless of their country of entry. As the statistician we interviewed at UDI put it, "Quota system is important because ... it is not the asylum seeker but the system [that] decides where a person will go. It also organizes collective systems of transporting these people, so an efficient solution." ${ }^{29}$ When efficiency becomes the ultimate goal of setting up systems, however, the day-to-day implications of software solutions for what is an increasingly complex legal, judicial, and humanitarian problem disappear.

Software creates its own inclusions and exclusions. As it was explained to us, every morning UDI receives an email about new registrations; but "born in reception system does not necessarily mean the baby was born last night." ${ }^{30}$ Instead, the baby might have been added to the system last night to parents who were already registered in the system-so there was a time lag. A time lag also emerges in death registrations, as it becomes complicated to register deaths when people do not have a PIN and hence do not ap- pear as if they are residents in data. According to a statistician at Statistics Norway, "you need an infrastructure" to be able to overcome such issues with registration of deaths and births; "it is not impossible, but it costs too much to develop [it] and we can't just do this for fun." ${ }^{31}$ This is one of the main reasons, for instance, why asylum seekers "are not allowed to marry": even though marriage could grant them a right to reside, registering the marriage of a person without a PIN is not technically possible. ${ }^{32}$

Thus, in the Norwegian context, there is an important politics of small numbers at play. The number of successful asylum applications is expected to be too small to warrant an infrastructural change to issue a PIN to them. Whether it is the uncertainty of their continued residence or likelihood of making successful asylum applications, limiting access to the PIN is a way of preventing them from accessing the welfare services available to residents. In a way, then, PIN also works as a border control device; it acts as a reminder of a border, even when individuals are residing in the country.

\section{DISCUSSION AND CONCLUSION}

In this article, we proposed that with software being celebrated as an objective, efficient, and low-cost alternative to existing systems of data collection and analysis, there is little room, if any, to take into account individual circumstances in the decision-making process in welfare provisions. While bias and discrimination often constitute the central analysis point of studies on algorithms and autonomous decision-making systems, we argued that their role in preventing individual voices from challenging how they are identified, categorized, and sorted in data is also a major issue. We showed that the logic of datafication and automatization leads to making decisions based on the costs of uprooting existing database infrastructures and data requirements, and not on individual needs or circumstances. We also showed that the need for data standardization leads to limiting (or preventing) the access of asylum seekers to welfare services, even in countries that are considered to be the most generous welfare states. We consider this as part of the dismantling of the welfare state as the decision to exclude one part of the population due to their (uncertain) residency status indicates that access to welfare is no longer a universal human right.

Our findings have important implications for thinking about the implications of software-based decisions, which are increasingly common in welfare provisions. Below we will summarize these through two aspects: accountability and data justice.

One important implication is related to accountability for decisions. In increasingly complex database infrastructures, who/which organization is responsible for which decision becomes very difficult to assess. By stressing that the decision is a result of a technical limitation-in our case, no PIN is issued to asylum seekers-the institutions diffuse responsibility and accountability from the political reasons for excluding asylum seekers from welfare state services.

27 Interview, UDI: Norway, April 2017.

28 The Dublin Regulation establishes that the initial Member State where an asylum application is lodged is responsible for the examination of the asylum application; accessed 21 November 2019, https://ec.europa.eu/home-affairs/what-we-do/policies/asylum/examination-ofapplicants en.

29 Interview, UDI: Norway, April 2017.

30 Interview, UDI: Norway, April 2017.

31 Interview, Statistics Norway, April 2017.

32 Interview, Statistics Norway, April 2017. 
This also diffuses accountability when things go wrong, such as when asylum seekers lose their lives in transit or lose contact with family members as they are relocated from one country to another. Accountability also presents a problem when not all those who are part of the database management of asylum applications are skilled at data processing techniques; or when they are unaware of the immediate implications of how data is entered, stored, and handled when it comes to populations seeking humanitarian protection. A typo in registering an asylum seeker's name or their origin country can result in immediate rejection, as these details are increasingly screened, sorted, and analyzed through multiple connected databases.

The changing practices in production of data on asylum seekers and refugees also have implications for data justice. Taylor $(2017,6)$ summarizes three approaches for thinking about data justice: (1) data used for governance can support power asymmetries (Johnson 2014); (2) data technologies can provide greater distributive justice through making the poor visible (Heeks and Renken 2016); (3) how practices of dataveillance can impact the work of social justice organizations (Dencik, Hintz, and Cable 2016). In the context of asylum seekers, we think the first approach is especially pertinent to the vulnerabilities they face.

The increasing connection of operational databases produced and managed by border and migration agencies with those of statistical ones entail that if a person or a characteristic is not significant enough to be included operationally, that person or characteristic is also excluded from statistics. This creates and exacerbates important power asymmetries. Border agencies might not be interested immediately in the educational qualifications, underlying healthcare concerns, or labor market aspirations of those crossing the borders. In population statistics, however, such characteristics play an important role for planning and developing policies for societies. But when the software packages that are used between departments are designed with operational logics in mind, rather than the social, economic, and other implications for individuals who are represented in data, it becomes difficult to assess the priorities for collecting the data. Is the priority managing migration numbers, or is it ensuring justice and equality for those who are resident in a country? We think it is important to pay attention to what kind of thinking is behind these data-based systems that are used to identify, sort, and keep a record of asylum seekers. Madianou (2019) draws attention to the fact that the databases and software programs used in humanitarian assistance are increasingly built with a logic of capitalism: they measure success based on lowering costs and increasing profits - and not necessarily on universal access to welfare or decommodification as a human right. The development of these databases and software programs is also increasingly outsourced to private vendors or privatepublic partnerships to cut down on public spending, which further indicate that business rather than welfare is the first consideration.

Moreover, fair representation in data is an important aspect of achieving data justice and overcoming power asymmetries. The ability to delete information from one's data or the capability to ask for amendments to be made to one's records is central to achieving fair representation in data for asylum seekers. In some countries, once refugees are naturalized -that is, once they acquire citizenship-their "refugee background" is automatically deleted from the data as their data is transferred to the central population register. But this is not always the case. In Norway, for instance, "refugee background" exists as a category that never gets deleted; and even when refugees are naturalized, their refugee background and their children's are kept in the records. There might be statistical reasons for doing so (e.g., to compare integration levels, for instance); but it remains a question of social justice when usual residents are asked to share their background details with the government (e.g., data related to identity such as religion and ethnicity are not collected in Norway), but individuals with a refugee background are not given the option to stop being refugees in data. In Finland, information on residence permit is removed immediately after naturalization. However, the method of assigning 1 January as the date of birth to those without valid identity documents during registration makes their background potentially recognizable and them potentially identifiable in data. We consider this a broad issue of ethics. Asylum seekers are not in a position to refuse to share their data (including biometric and personal data) with government officials, humanitarian agencies, or international organizations. With data increasingly shared across various platforms and databases to make decisions on their cases, it becomes a question of how this data is handled in a fair manner.

Moreover, Dencik et al. (2016) draw attention to the political agenda that is driving the implementation of extensive data surveillance organized around risk management and securitization of borders, and not asylum as a fundamental human right. In this article, we showed that asylum seekers are not issued PINs, and they are not included in the central population registers. This, however, does not mean that there is lack of data production on asylum seekers. If anything, it can be argued that the principles of data minimization, response burden, and the anonymity and privacy of individuals - which are fundamental tenets of statistical data production-often do not apply to the case of asylum seekers; and practices that could be interpreted as surveillance are often normalized when it comes to them. From the celebration of retina scans as a form of identification ${ }^{33}$ to the ubiquitous use of biometrics for identifying and tracking individuals, there seems to be no information that is too private to collect and no data that is too personal to store when it comes to those claiming asylum (also see Madianou 2019). This is why we think that data-based systems are not expanding the scope of welfare systems due to the abundance of new and more types of data, but instead are having the opposite effect as these data become border control devices-acting as a reminder of a border, even when asylum seekers are residing in the country or refugees have become naturalized citizens. This we call a data justice issue.

\section{FUNDING}

The authors have disclosed receipt of the following financial support for the research, authorship, and/or publication of

33 Charlie Dunmore, “Iris Scan System Provides Cash Lifeline to Syrian Refugees in Jordan,” UNHCR, 23 March 2015, accessed 21 November 2019, https://www.unhcr.org/uk/news/latest/2015/3/550fe6ab9/iris-scan-system-provides-cash-lifeline-syrian-refugees-jordan.html. 
this article:

The research leading to this publication based on the "ARITHMUS: How Data Make a People" project has received funding from the European Research Council (ERC) under the European Union's Seventh Framework Programme (FP/ 2007-2013)/ERC Grant Agreement no. 615588. Principal investigator, Evelyn Ruppert, Goldsmiths, University of London.

The "Mobile People-Challenging the Population Statistics and Projections" project has received funding from the Kone Foundation (2012-2016). Principal investigator, Marja Alastalo, University of Eastern Finland.

\section{ACKNOWLEDGMENTS}

We thank the two anonymous reviewers and the editors of the special issue "Datafication and the Welfare State," Dr. Lina Dencik and Dr. Anne Kaun. We also thank all our collaborators at ARITHMUS project (Prof. Evelyn Ruppert, Dr. Baki Cakici, Dr. Francisca Grommé, Dr. Stephan Scheel, and Dr. Ville Takala and the Mobile People project (Dr. Anitta Kynsilehto, Dr. Riikka Homanen, and Pekka Rantanen). The Norway case study in this article is based on the ARITHMUS project, and the Finland case study is based on the Mobile People project.

The authors express no conflicts of interest.

\section{AUTHOR BIOGRAPHIES}

Funda Ustek-Spilda is a post-doctoral researcher at the Oxford Internet Institute, University of Oxford. She currently works for Fairwork Foundation, a project interested in studying work practices and fairness standards in the gig economy. Previously she held post-doctoral positions at London School of Economics (VIRT-EU: Values and Ethics in Innovation for Responsible Technology in Europe) (2018-2019) and Goldsmiths, University of London (ARITHMUS: How data make a people) (2014-2018). She is interested in studying ethics, justice and fairness in relation to data and technology, with a particular focus on gender, labour and migration. She holds a D.Phil from the University of Oxford in Sociology.

Marja Alastalo is a university lecturer in sociology at the University of Eastern Finland. Her fields of expertise are science and technology studies and sociology of quantification. In her empirical studies she has explored population and migration statistics, indicators, standardization of statistics in the EU and social research methods. Currently she is working on a project called Data-Driven Society in the Making, where she focuses on data-driven technologies and practices in public social and health care and their effects on knowledge production and governance. 


\section{REFERENCES}

Aradau, Claudia, and Tobias Blanke. 2018. "Governing Others: Anomaly and the Algorithmic Subject of Security.” European Journal of International Security 3 (1): 1-21. https://doi.org/10.1017/eis.2017.14.

Baeten, Guy, Lawrence D. Berg, and Anders Lund Hansen. 2015. "Introduction: Neoliberalism and Post - Welfare Nordic States in Transition.” Geografiska Annaler: Series B, Human Geography 97 (3): 209-12. https://doi.org/10.1111/geob.12075.

Bloch, Alice, and Liza Schuster. 2002. "Asylum and Welfare: Contemporary Debates.” Critical Social Policy 22 (3): 393-414. https://doi.org/10.1177/02610 1830202200302.

Boucher, Anna, and Justin Gest. 2014. "Migration Studies at a Crossroads: A Critique of Immigration Regime Typologies.” Migration Studies 3 (2): 182-98. https://doi.org/10.1093/migration/mnu035.

Bowker, Geoffrey C., and Susan Leigh Star. 2000. Sorting Things Out: Classification and Its Consequences. Cambridge, MA: The MIT Press. http s://doi.org/10.7551/mitpress/6352.001.0001.

Bozdag, Engin. 2013. “Bias in Algorithmic Filtering and Personalization." Ethics and Information Technology 15 (3): 209-27. https://doi.org/10.1007/s1 0676-013-9321-6.

Cakici, Baki, and Evelyn Ruppert. 2020. "Methods as Forces of Subjectivation: Experiments in the Remaking of Official Statistics." Journal of Cultural Economy 13 (2): 221-35. https://doi.org/10.1080/175 $\underline{30350.2019 .1684340 .}$.

Caplan, Jane, and John Torpey. 2001. Documenting Individual Identity: The Development of State Practices in the Modern World. Princeton and Oxford: Princeton University Press. https://doi.org/10.1515/97 $\underline{80691186856 .}$.

Cheney-Lippold, John. 2017. We Are Data: Algorithms and the Making of Our Digital Selves. New York: NYU Press. https://doi.org/10.2307/i.ctt1gk0941.

Christopher, A.J. 2009. "Delineating the Nation: South African Censuses 1865-2007.” Political Geography 28 (2): 101-9. https://doi.org/10.1016/i.po lgeo.2008.12.003.

Crompton, Rosemary. 1998. "Women's Employment and State Policies." Innovation: The European Journal of Social Science Research 11 (2): 129-46. https://do i.org/10.1080/13511610.1998.9968558.
Curtis, Bruce. 2001. The Politics of Population: State Formation, Statistics, and the Census of Canada, 1840-1875. Toronto: University of Toronto Press. http s://doi.org/10.3138/9781442682108.

Dencik, Lina, Arne Hintz, and Jonathan Cable. 2016. "Towards Data Justice? The Ambiguity of AntiSurveillance Resistance in Political Activism.” Big Data \& Society 3 (2): 205395171667967. https://doi.or $\mathrm{g} / 10.1177 / 2053951716679678$.

EGRIS. 2018. International Recommendations on Refugee Statistics'. Luxembourg: European Union and the United Nations.

Esping-Andersen, Gøsta. 1990. The Three Worlds of Welfare Capitalism. Cambridge: Polity Press.

Eubanks, Virginia. 2018. Automating Inequality: How High-Tech Tools Profile, Police, and Punish the Poor. New York: St. Martin's Press.

Fenger, H.J.Menno. 2007. “Welfare Regimes in Central and Eastern Europe: Incorporating Post-Communist Countries in a Welfare Regime Typology." Contemporary Issues and Ideas in Social Sciences 3 (2). https://repub.eur.nl/pub/34876/metis_129323.pd f.

Gal, John. 2010. "Is There an Extended Family of Mediterranean Welfare States?” Journal of European Social Policy 20 (4): 283-300. https://doi.org/10.1177/ $\underline{0958928710374374}$.

Goodman, Roger, Gordon White, and Huck-ju Kwon. 1998. The East Asian Welfare Model: Welfare Orientalism and the State. London: Psychology Press.

Gough, Ian. 2013. "Social Policy Regimes in the Developing World.” In A Handbook of Comparative Social Policy, edited by Patricia Kennett, 205-24. Cheltenham, UK: Edward Elgar Publishing.

Greve, H. R. 2007. “Exploration and Exploitation in Product Innovation.” Industrial and Corporate Change 16 (5): 945-75. https://doi.org/10.1093/icc/dt $\underline{\mathrm{m} 013}$.

Griffiths, Melanie. 2012. "Vile Liars and Truth Distorters'; Truth, Trust and the Asylum System.” Anthropology Today 28 (5): 8-12. https://doi.org/10.1 111/j.1467-8322.2012.00896.x.

Guardian. 2019. “Automating Poverty,” October 21, 2019. https://www.theguardian.com/technology/serie s/automating-poverty. 
Heeks, Richard, and Jaco Renken. 2016. “Data Justice For Development: What Would It Mean?” Manchester. 2016. https://www.gdi.manchester.ac.uk/ research/publications/otherworking-papers/di/di-wp6 3/.

Horvath, Kenneth, Anna Amelina, and Karin Peters. 2017. "Re-Thinking the Politics of Migration. On the Uses and Challenges of Regime Perspectives for Migration Research." Migration Studies 5 (3): 301-14. https://doi.org/10.1093/migration/mnx055.

Johnson, Jeffrey Alan. 2014. "From Open Data to Information Justice." Ethics and Information Technology 16 (4): 263-74. https://doi.org/10.1007/s1 0676-014-9351-8.

Kangas, Anita, and Jill Onsér - Franzén. 1996. “Is There a Need for a New Cultural Policy Strategy in the Nordic Welfare State?" The European Journal of Cultural Policy 3 (1): 15-26. https://doi.org/10.1080/1 0286639609358031.

Kettunen, Pauli, and Klaus Petersen, eds. 2011. Beyond Welfare State Models: Transnational Historical Perspectives on Social Policy. Cheltenham, UK: Edward Elgar Publishing.

Kvist, Jon, and Bent Greve. 2011. "Has the Nordic Welfare Model Been Transformed?” Social Policy \& Administration 45 (2): 146-60. https://doi.org/10.111 1/j.1467-9515.2010.00761.x.

Law, John. 2004. After Method: Mess in Social Science Research. London: Routledge. https://doi.org/10.432 4/9780203481141.

Law, John, Evelyn Ruppert, and Mike Savage. 2011. “The Double Social Life of Methods." In CRESC Working Paper Series 95.

Leibler, Anat, and Daniel Breslau. 2005. “The Uncounted: Citizenship and Exclusion in the Israeli Census of 1948." Ethnic and Racial Studies 28 (5): 880-902. https://doi.org/10.1080/0141987050015891 9.

Lewis, Jane. 2006. "Men, Women, Work, Care and Policies.” Journal of European Social Policy 16 (4): 387-92. https://doi.org/10.1177/0958928706068276.

Madianou, Mirca. 2019. “The Biometric Assemblage: Surveillance, Experimentation, Profit, and the Measuring of Refugee Bodies." Television \& New Media 20 (6): 581-99. https://doi.org/10.1177/152747 6419857682.
Mayblin, Lucy. 2016. “Troubling the Exclusive Privileges of Citizenship: Mobile Solidarities, Asylum Seekers, and the Right to Work." Citizenship Studies 20 (2): 192-207. https://doi.org/10.1080/13621025.20 15.1132570 .

Midgley, James. 1997. Social Welfare in Global Context. California: SAGE Publications, Inc. https://d oi.org/10.4135/9781483327945.

Mittelstadt, Brent Daniel, Patrick Allo, Mariarosaria Taddeo, Sandra Wachter, and Luciano Floridi. 2016. "The Ethics of Algorithms: Mapping the Debate." Big Data \& Society 3 (2): 205395171667967. https://doi.or $\mathrm{g} / 10.1177 / 2053951716679679$.

Mountz, Alison. 2011a. "Where Asylum-Seekers Wait: Feminist Counter-Topographies of Sites between States.” Gender, Place \& Culture 18 (3): 381-99. http s://doi.org/10.1080/0966369x.2011.566370.

- - - 2011b. "Specters at the Port of Entry:Understanding State Mobilities through an Ontology of Exclusion.” Mobilities 6 (3): 317-34. http s://doi.org/10.1080/17450101.2011.590033.

Orloff, Ann Shola. 2009. "Gendering the Comparative Analysis of Welfare States: An Unfinished Agenda.” Sociological Theory 27 (3): 317-43. https://doi.org/1 0.1111/j.1467-9558.2009.01350.x.

Pasquale, Frank. 2015. The Black Box Society: The Secret Algorithms That Control Money and Information. Cambridge, MA: Harvard University Press. https://doi.org/10.4159/harvard.978067473606 1.

Pierson, Christopher, and Francis G. Castles. 2009. The Welfare State Reader. 3rd ed. Cambridge: Polity Press.

Roberts, Stephen L, and Stefan Elbe. 2017. "Catching the Flu: Syndromic Surveillance, Algorithmic Governmentality and Global Health Security.” Security Dialogue 48 (1): 46-62. https://doi.org/10.11 77/0967010616666443.

Rouvroy, A. 2013. “The End(s) of Critique: Data Behaviourism versus Due Process.” In Privacy, Due Process, and the Computational Turn: The Philosophy of Law Meets the Philosophy of Technology, edited by M. Hildebrandt and E. De Vries, 143-68. Abingdon: Routledge.

Ruppert, Evelyn S. 2008. “'I Is; Therefore I Am”: The Census as Practice of Double Identification." Sociological Research Online 13 (4): 69-81. https://do i.org/10.5153/sro.1778. 
Scott, James C. 1998. Seeing Like a State: How Certain Schemes to Improve the Human Condition Have Failed. New Haven, CT: Yale University Press.

Silva, Selena, and Martin Kenney. 2018. "Algorithms, Platforms, and Ethnic Bias: An Integrative Essay.” Phylon 55 (1/2): 9-37.

Taylor, Linnet. 2017. "What Is Data Justice? The Case for Connecting Digital Rights and Freedoms Globally.” Big Data \& Society 4 (2): 205395171773633. https://doi.org/10.1177/205395171 $\underline{7736335}$.

Tervonen, Miika, Saara Pellander, and Nira YuvalDavis. 2018. "Everyday Bordering in the Nordic Countries.” Nordic Journal of Migration Research 8 (3): 139. https://doi.org/10.2478/njmr-2018-0019.

Thränhardt, Dietrich. 1999. “Germany’s Immigration Policies and Politics.” In Mechanisms of Immigration Control. A Comparative Analysis of European Regulation Policies, edited by G. Brochmann and T. Hammar, 29-57. Oxford: Berg.

UNECE. 2007. Register-Based Statistics in the Nordic Countries: Review of Best Practices with Focus on Population and Social Statistics. New York: UN Economic Commission for Europe (UNECE.

- - - 2015. CES Recommendations for the 2020 Censuses of Population and Housing'. ECE/CES/41. Geneva: UN Economic Commission for Europe (UNECE.
Ustek-Spilda, Funda. 2019. “Statisticians as BackOffice Policy-Makers: Counting Asylum-Seekers and Refugees in Europe.” Science, Technology, \& Human Values 45 (2): 289-316. https://doi.org/10.1177/01622 43919882085 .

Ustek-Spilda, Funda, Alison Powell, and Selena Nemorin. 2019. "Engaging with Ethics in Internet of Things: Imaginaries in the Social Milieu of Technology Developers.” Big Data \& Society 6 (2): 205395171987946. https://doi.org/10.1177/205395171 9879468.

Vetters, Larissa. 2007. “The Power of Administrative Categories: Emerging Notions of Citizenship in the Divided City of Mostar1.” Ethnopolitics 6 (2): 187-209. https://doi.org/10.1080/1744905070134500 9.

Vis, Farida, and Olga Goriunova. 2015. “The Iconic Image on Social Media: A Rapid Research Response to the Death of Aylan Kurdi." In Report; Part of the "Picturing the Social: Transforming Our Understanding of Images in Social Media and Big Data Research” Project. Visual Social Media Lab.

Whittaker, Meredith, Kate Crawford, Roel Dobbe, Genevieve Fried, Elizabeth Kaziunas, Varoon Mathur, Sarah Mysers West, Rashida Richardson, Jason Schultz, and Oscar Schwartz. 2018. AI Now. New York University: AI Now Institute. 